\title{
Education of the 21st century - Social Learning with SAP solutions
}

\author{
Rob Jonkers ${ }^{1}$, SAP \\ 1Director of IBU Solutions Education \& Research| Solution Management, Rob.Jonkers@sap.com \\ Keywords \\ Social Learning, Collaboration, LMS, SLCM, SAP, Student Lifecycle Management.
}

\begin{abstract}
1. ABSTRACT
Education institutions today face huge challenges in order to fulfill the demands of their student 'customers' and manage their success. In the $21^{\text {st }}$ century, these key customers are used to communicating and collaborating at any place, and at any time on personal matters, and they expect to manage their academic lifecycle in the same manner. The challenges for the education institutions are to embed these requirements in their initial strategy, and position the technology for availability, execution and operation.
\end{abstract}

SAP Success Factors provides the opportunity to leverage our 'administration' focused Student Information System (SIS) called SAP Student Lifecycle Management (SLCM) to a higher level; a 'Learning Platform' level. This learning portfolio functionally extends both a best-in-class leading cloud collaboration tool with a world class cloud LMS system. These solutions bring the potential to enable our SIS with both 'social learning' capabilities, with E-Learning and Virtual Classroom capabilities.

The major driver for SAP development of this integration is the market demand for a cloud-based 'learning platform' that enables an education institution to mobilize the student lifecycle with 'collaboration' and 'delivery' services.

In this presentation the diverse components/services of the integration will be discussed and demonstrated by real use cases. The presentation also includes a live demonstration of several components of that 'Learning Platform'.

\section{PAPER}

Distance Learning is increasingly becoming a more integral part of current educational institution operations. Education is no longer restricted to a particular place and time within brick and mortar structures.

The challenging schedules of the 21st century, along with increasingly virtual global education opportunities, drive the diverse needs of researchers and students and their demand for a 24h online study experience where each individual can manage their education lifecycle and 'learn' at any time and place. While options for 'distance learning' have been available for some time, these services are often discrete and focused on narrow applications.

The element of real-time interaction and the cross-integration of ideas are often impossible. The envisioned solution is to enable distance learning and real social collaboration across channels, where students and scholars can take advantage of each other's knowledge-share on a single fully integrated mobile 'learning/education' platform.

This envisioned platform will avoid information sharing barriers and time delays, and will allow immediate thought exchange and collaboration, to focus ideas and drive the best solutions.

About SAP: SAP for Higher Education \& Research solutions support efficiency by enabling standardization and the use of best business practices across your organization, allowing you to build a solid business foundation that supports your institutional mission. At the same time, the solutions also enable you to invest in innovation, enhancing the core teaching and research activities that distinguish your institution from competitive organizations. 
SAP for Higher Education \& Research solutions support a full range of organizational processes including student lifecycle management, research management, grants management, financial management, operations, human resources, procurement, analytics, and reporting. The goal is to help you enhance student services, improve operational performance, and sustain the innovation that makes your institution unique and successful.

\section{BIOGRAPHY}

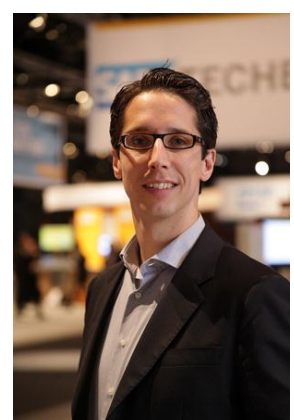

Rob Jonkers was born in the Netherlands and received his Human Resources Bachelor degree at Fontys University. Rob started his career as an IT system engineer and joined SAP in 2006 as an SAP HR consultant to drive the combination of IT and HR in practice. Since 2007 Rob focused on 'Education' in the corporate context and academic context. Later he specialized in the pure academic side of education in the context of SAP solutions like SAP Student Lifecycle Management. Rob has supported diverse projects for SAP in an international environment, and the experience has enabled him to excel in his current role within Solution Management of SAP. Currently, Rob is focused on bringing innovation to the Education Market with SAP's solution portfolio. 